\title{
The Ethics of RFID Technology
}

\author{
Joël Schlatter and Fouad Chiadmi \\ University Hospital of Jean Verdier
}

France

\begin{abstract}
'Everyone's right to life shall be protected by law. No one shall be deprived of his life intentionally save in the execution of sentence following his conviction of a crime for which this penalty is provided by law. Deprivation of life shall not be regarded as inflicted in infringement of this Article when it results from the uses of force which is no more than absolutely necessary: (a) in defence of any person from unlawful violence; (b) in order to effect lawful arrest to prevent the escape of a person lawfully detained; (c) in action lawfully taken for the purpose of quelling riot or insurrection.'
\end{abstract}

(Korff, 2006)

\section{Introduction}

In the Parisian subway, a passenger quickly passes through the terminal of the subway without showing a ticket. The terminal indicates by a sound and a visual sign that the passage is allowed and the door is automatically unbolted. The passenger passes his bag at a distance of a few centimetres above the terminal, containing a Navigo chart integrating an RFID chip. The personal information is transmitted to the data processing unit in real-time and analyzed. The passage of the person is thus traced.

When passing through US customs, the traveller shows his passport to the American official who passes it on to a reader. Thus, it immediately obtains all information of the passenger. On the chip all information found on the old passport is recorded and by this technique police controls are more easily facilitated and false passports detected.

In Rotterdam or Barcelona, VIP visitors of Baja Beach Clubs are identified by a subcutaneous chip developed by the company Applied Digital Solutions (ADS). This chip is also used as a credit card without contact. ADS developed the VeriChip, a subcutaneous chip the size of a grain of rice, allowing applications of security access to buildings, such as for the identification of patients in hospitals or security against abduction in South America.

With these examples, we see de facto that the RFID technology applied to humans or objects immediately generates many questions about the right to a private life because of its somewhat suspect nature, in particular, when recording personal data. Doubts about the justification of the collection of data or on the storage of data and on the protection against access by third parties are revealed. If these fears prove to be relevant, it will be necessary for us either to espouse refusal of the technology in the name of respect for freedom, or, in the name of a defence of inescapable progress, to find the form of political society where the definition of freedom would not inevitably include a right to anonymity. It will thus be 
necessary for us to see, on the basis of the fear of the individuals towards technology, if one can plan to reconcile freedom and technology, in a society where humans see guaranteed freedom and where the use of constantly evolving technology does not dehumanize. Hobbes proposed that fear is caused by the threat of violence and thus the state is created with the role of protecting individuals. But he points out to us another passion associated with this fear which is the ceaseless desire to enjoy life and secure more pleasure, and the role of the state must also therefore be to protect and guarantee peace.

The fear of individuals of this type of technology, but also the desire to have it, are expressed openly and thus the question that should be posited with regard to politics is: does RFID go against a political society where the individuals are free or does RFID better contribute to the maintenance of political society?

\section{RFID Technology and instinctive fears}

In defence of their freedom, individuals are afraid of being constantly supervised, cardindexed or tracked without their consent. The ultimate fear is that of the shrouded arrival of a society where there would be no more freedom, in other words, the imposition of a totalitarian state. One could certainly interpret the fear of RFID technology and this concern with regard to losing freedom as simple paranoia, but it should not be forgotten that this fear also has historical precedent. The totalitarian societies of the 20th century did not hesitate to categorize individuals according to their race, religious affiliation, politics etc. and then to exterminate some of them, according to the profiles thus drawn up. In the concentration camps, as it was the case in Auschwitz, numbers were tattooed on the skins of prisoners, contributing to the process of dehumanization. One can understand that the loss of freedom represents a fear for the $21^{\text {st }}$ century. In this direction, the pure and simple refusal of RFID technology could be an obvious and radical solution to preserving freedom. The technological advancement would increase the danger, and the capacity to harm, of a totalitarian society. Therefore, the question should be asked: does the application of this technology carry in it the germ of the advent of a totalitarian society?

On the basis of the postulate that we live in a liberal society, where the freedom of each individual is preserved and does not harm that of others, we can suppose that the fear of citizens to losing their freedom because of a technological advance would be related to the disappearance of a political society which is only capable of guaranteeing this freedom. It is necessary for us to determine whether or not RFID is compatible with a certain idea of liberalism, but in addition, it is necessary to keep in mind that liberalism can also mean the freedom of business or 'free trade'.

The second human passion exposed by Hobbes is fear. From it arises the request for safety, since humans have the desire to preserve themselves. It is thus fear, a motive of human action, which leads to the centralised capacity of the state in Hobbes' design. Fear thus generates mistrust. In this design, RFID allows for data collection to be in the hands of the state, meaning access to the data collected by the society is possible when important issues are called upon. The state does not itself need to collect this data since industry takes care of this in part, but it can of course decide to impose identity RFID cards upon citizens, in which case it would have the techniques to control at any moment each citizen individually. The modern individual expects the state to protect, which gives to the state the obligation to do everything to anticipate the worst. However, RFID facilitates forecasts by providing considerable amounts of reliable information, fast. The fear of terrorism constitutes a 
sufficient motive to encourage the state to use the data given by RFID technology to operate a better monitoring system, as any individual potentially represents a threat to others. Of course that raises the question of the respect due to private life, but this requirement is not at the heart of Hobbes' design of the state.

RFID technology makes possible, in theory, the identification of all things in the world but at the same time it causes in many people the fear of permanent monitoring. The critical approaches as to the employment of RFID technology relate mainly to this threat to the private life. Action groups, such as CASPIAN, led by Katherine Albrecht, categorize RFID chips as being 'spy chips'.

But a contrario, RFID can release a human being from daily constraints and thus enable him to fulfil his desires more easily. Today, patients voluntarily agree to have a chip placed in the arm so that there is no error of attribution on their medical file. Tomorrow, we will certainly agree to be chipped because that will give us privilege, of rights or accessibilities, thus RFID technology is ambivalent, tearing the individual between the desire to facilitate existence and the fear of a loss of freedom, in particular in the private sphere.

\section{RFID Technology and interconnection of all things in the world}

It is necessary to widen the narrow field of RFID, to position it in the scope of broader development, that of the 'Internet of things'. After a report by the ITU (International Telecommunication Union, 2005) the Internet of things represents a technological revolution which gathers developments in various fields, such as the techniques of communication without contact. From now on the question of the things will relate to those which think, which communicate between each other and react with their medium. 'Indeed, with the benefit of integrated information processing, industrial products and everyday objects will take on smart characteristics and capabilities. (...) eventually, even particles as small as dust might be tagged and networked. Such developments will turn the merely static objects of today into newly dynamic things, embedding intelligence in our environment and stimulating the creation of innovative products and entirely new services.' This revolution is not science fiction. This development is considered inevitable. RFID then plays a part in broader developments, potentially with the wireless connectivity of the things, allowing communication and interaction. The various applications of RFID contribute with other developments, such as mobile telephony, Bluetooth and GPS (Global Positioning System) with the interconnection of all the things in the world. Such technologies will contribute to the realization of futuristic visions, such as the automated house which allows the connection of the house with the outside world without direct contact.

Kenneth F. Fishkin and Jay Lundell outlined the possibilities of a system of observation and warning for the elderly. In their project they imagine the following situation. A man, Chester, is 90 years old and lives alone in a house. His daughter, Molly, lives a few kilometres away. The researchers propose to equip all the objects in the house with RFID markers. Chester himself carries a reader in his clothing. Thus it is possible to rebuild his entire timetable and by processing the data also recover Chester's entire manner of living. The revolution in the interconnection of all the things in the world is not a unilateral development, but a term which gathers multifarious developments. Thus, the Internet of things will have a broad impact on many processes of life that characterize our daily existence and potentially influencing our behaviour.

But is the passage of information using RFID technology protected? Is the coding of the information transmitted by the chip placing it in the private life of people? The first 
disadvantage concerning subcutaneous chips is that they are not protected. If the computer age has taught us one thing it is that systems and the data are always less protected than is said and although the chips, such as VeriChip, are marketed for access control, they lack protection. In a recent publication in the Journal of the American Medical Informatics Association (JAMIA), Ari Juels showed that VeriChip has no more protection than a code bar and that it was very simple to build an object able to scan a VeriChip (Juels, 2006). The vulnerability of RFID chips does not protect us from those who would deploy them as sedentary tools and the data which will compose this type of chip will never be completely protected or confidential. That means that there are certain applications which these technologies will never be able to carry out. It should be understood that the asset of these technologies, and in particular of this one, is not to make the world a safer place. The goal, if there is one, is to simplify the use of it, to return the world to a more malleable and less formalized place. The issue is not to make safe, control, sign and certify, but to create a new place for the abstract one which already composes our relations with the world, the objects and others. The risk, and there is one, is that more and more applications have only one access key, too fragile to be worthy of confidence.

\section{RFID Technology in relation to man}

The technology brought upheaval to our world and invaded all fields. The general tendency is then to declare oneself for or against the technology. The technology plays a great part in the constitution of our lives. The relations between the human and the technology are not neutral since they enable us to increase the standard of living when comfort has become unceasingly important. But humans fear losing control, to be worked and controlled by the technology. The seizure of humans by the technology is understood, like hybridization or progressive fusion of human and technology. Hybridization takes the form of a progressive delegation of the body's functions, like intellectual functions and the determination of human behaviour. RFID technology thus tends to influence us in multiple ways. Generally this influence functions while intervening in the relations which we constitute with others and by which our lives are structured. Engagement in the ethics of the technology gives the required authority to conclude hybridization. It is by the imposition of the laws that developments described as intolerable by the majority of people could be born. But a whole field of hybridization escapes legislation. By hybridization with technology, the human integrates new forms of use of the technology and brings about novel modes of life. In addition, these practices create new forms of existence. It is not a question of freedom or autonomy against the technology, but of an attitude toward practices which do not want to only undergo a shaping by the techniques, but aims at establishing an autonomy which consists in shaping of oneself. It is not a question either of a categorical denunciation of RFID, on the basis of universal principles of autonomy which would prevent conscious engagement in relations of constraints. It is about an attitude of recognition and acceptance of RFID technology. Such is the message of the ethics of constituting oneself through the use of the technology.

Let us take the Navigo system in the Parisian subway as an example. It is clear that the Navigo system imposes behaviours on the users. All the technical devices in the subway, such as the terminals, direct the behaviour of people. This development is not understood as an imposition, but rather as a progressive engagement in structured procedures. The introduction of the Navigo system increased the sale of yearly subscriptions, which 
indicates that people gradually wish to benefit from the Navigo master key and accept integration with the system.

\section{RFID technology and human desire}

Accordingly, RFID allows the human passions expressed in the state of nature to be appeased. If RFID allows the collection of information on the purchases of individuals, this can potentially be made known to companies. With information on the type of goods individuals want to enjoy, when, at what frequency etc., companies can then do everything to ensure the individual has all he wants, even before he formulates his desire, since RFID allows for envisaging desires to come. It can also better stimulate this desire by 'profiling' the customer in order to create publicities which cause him to desire buying and to consume more intensely. RFID is a tool which returns the work of modern companies even faster, more precisely and more completely: human desire being insatiable by definition, the companies continue to produce their products and produce them as long as this desire is maintained. The information furnished by RFID should allow for even more important marketing, made more reliable as it is supported on precise, real data. Since the state is what allows the development of economic activity, from this point of view the state could not be opposed to the use of RFID, in that it contributes to the search of pleasure.

What about those who do not wish to consume, or do not consume according to the discounted forecasts, or who refuse to allow their private information to be gathered on a database? They will not be able to benefit from the advantages granted to the remainder of the consumers. Under the increased pressure of publicities, presented as more individual and instrumentalized, is there a real risk that social links transform under this impulse into a 'common bond' which would be that of the same desire formatted by industry? But the use of the data collected in any time and any place by RFID could well lead to a gradual standardization of the desire, i.e. part of passions. From this point of view, could RFID represent the efficient cause of a turning in the design of the social link? The individuals 'would thus be linked' by a social link rather than understood 'to wish for the same type of things'. This social link born of a common, or rather similar, desire would be then a 'fossilized' bond because it is registered in foreseeable diagrams. De facto, all those who refuse to see their data collected or do not consume in a foreseeable way, would then be excluded from this social link.

\section{Discussion}

RFID allows tracking and identifying things equipped with an RFID marker. This technology allows for the dream of tracing all the things and people in the world, but represents at the same time a fear of total monitoring. RFID poses problems with the private life. This time it is not the publication of images and facts on the personal life, but the collection and recording of the data for reasons of statistics and management. With the RFID technology, a new concept of private life appears. The daily use of the products equipped with RFID functions often returns a benefit of the specific services in exchange for the collection of information on the user. The arbitration of the state is then essential to control the exchanges of information emitted by the RFID by the constitution of the laws on the protection of information. One thus needs new distinctions between acceptable and unacceptable forms of tracing. The state has two complementary roles to play: to facilitate 
trade by the contribution of the RFID technique and to guarantee the safety of the information exchanges. Indeed, the use of RFID techniques in daily life involves a fear of insecurity insofar as the actions of people can be known in real-time (purchases, displacements, communications...). The private sphere then becomes permanently public. With RFID, humans lose the control of their own data and lifestyle choices. It involves itself in a process of hybridization with RFID techniques, implying an increase in its capacity on nature, but also dependence on the technique. The human being becomes a virtual being, a being of information to be collected in one way for thousands of companies. The exchanged information is instrumentalized and the desires of the individuals are standardized. The RFID technique creates a tension between the human need for safety and the need for freedom. But, the individual must determine what is more essential for him: fear of death, willingness to conserve life or fear of domination and the desire to be free. The ethical approach must be concerned here with the subjectification of people through the use of the technology.

\section{References}

Korff, D. 2006. The right to life. Guide to the implementation of Article 2 of the European Convention on Human Rights Strasbourg. Council of Europe, Human Right Handbooks $n^{\circ} 8$.

Hobbes, T. 2010. Leviathan: However the Matter, Form and Power of the Commonwealth, Ecclesiastical and Civil Library. Ed. Yale University Near. ISBN: 0300118384.

Graafstra, A. 2006. RFID Toys: Cool Projects for Home, Office and Entertainment. ED. John Wiley \& Sons Inc. ISBN: 0471771961.

Juels, A. 2006. The Practice of Informatics: Technology Evaluation: The Security Implications of VeriChip Cloning. JAMIA; 13:601 - 607 DOI:10.1197/jamia.M2143.

International Telecommunication Union. 2005. ITU Internet Carryforwards 2005: The Internet of Things. 7th edition, Geneva, www.itu.int/internetofthings. 


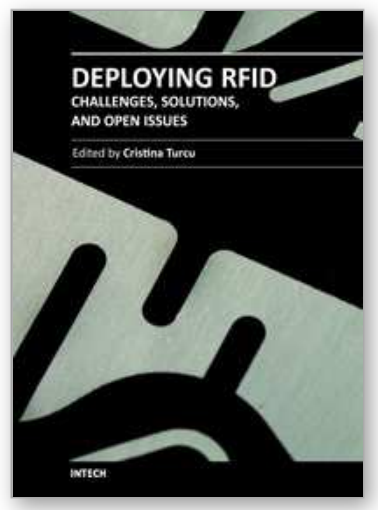

\author{
Deploying RFID - Challenges, Solutions, and Open Issues \\ Edited by Dr. Cristina Turcu
}

ISBN 978-953-307-380-4

Hard cover, 382 pages

Publisher InTech

Published online 17, August, 2011

Published in print edition August, 2011

Radio frequency identification (RFID) is a technology that is rapidly gaining popularity due to its several benefits in a wide area of applications like inventory tracking, supply chain management, automated manufacturing, healthcare, etc. The benefits of implementing RFID technologies can be seen in terms of efficiency (increased speed in production, reduced shrinkage, lower error rates, improved asset tracking etc.) or effectiveness (services that companies provide to the customers). Leading to considerable operational and strategic benefits, RFID technology continues to bring new levels of intelligence and information, strengthening the experience of all participants in this research domain, and serving as a valuable authentication technology. We hope this book will be useful for engineers, researchers and industry personnel, and provide them with some new ideas to address current and future issues they might be facing.

\title{
How to reference
}

In order to correctly reference this scholarly work, feel free to copy and paste the following:

Joël Schlatter and Fouad Chiadmi (2011). The Ethics of RFID Technology, Deploying RFID - Challenges, Solutions, and Open Issues, Dr. Cristina Turcu (Ed.), ISBN: 978-953-307-380-4, InTech, Available from: http://www.intechopen.com/books/deploying-rfid-challenges-solutions-and-open-issues/the-ethics-of-rfidtechnology

\section{INTECH}

open science | open minds

\author{
InTech Europe \\ University Campus STeP Ri \\ Slavka Krautzeka 83/A \\ 51000 Rijeka, Croatia \\ Phone: +385 (51) 770447 \\ Fax: +385 (51) 686166 \\ www.intechopen.com
}

\author{
InTech China \\ Unit 405, Office Block, Hotel Equatorial Shanghai \\ No.65, Yan An Road (West), Shanghai, 200040, China \\ 中国上海市延安西路65号上海国际贵都大饭店办公楼405单元 \\ Phone: +86-21-62489820 \\ Fax: $+86-21-62489821$
}


(C) 2011 The Author(s). Licensee IntechOpen. This chapter is distributed under the terms of the Creative Commons Attribution-NonCommercialShareAlike-3.0 License, which permits use, distribution and reproduction for non-commercial purposes, provided the original is properly cited and derivative works building on this content are distributed under the same license. 